\title{
Cutaneous Manifestations in Renal Transplant Recipients
}

\author{
Das $\mathrm{AK}^{1}$, Sharma $\mathbf{R}^{2}$, Karn $\mathrm{A}^{3}$
}

${ }^{1}$ Associate Professor, Department of Dermatology, Maharajgunj Medical Campus, Maharajgunj, Kathmandu; ${ }^{2}$ Consultant Dermatologist, Department of Dermatology, Green Pastures Hospital, Nayagaun, Pokhara; ${ }^{3}$ Medical Officer, Nepal Mediciti Hospital, Lalitpur, Nepal.

\begin{abstract}
Introduction: The availability of potent immunosuppressants has paved the path towards decreased incidence of graft rejection and long term survival of the renal transplant recipients. But, with the increased life span of the patients and long term use of immunosuppressants, there has been an increase in various skin conditions; ranging from various infections to some life-threatening cutaneous malignancies.

Objectives: This study was carried out to determine the pattern of different cutaneous manifestations in renal transplant recipients at Tribhuvan University Teaching Hospital, to identify the infectious and non-infectious skin manifestations in these patients and their relation with the duration of transplantation.

Materials and Methods: The present study was a hospital based cross-sectional descriptive study conducted at Tribhuvan University Teaching Hospital, Kathmandu; Department of Internal Medicine, Transplant Outpatient department and Outpatient department of Department of Dermatology from June 2013 to May 2014. A total of 114 renal transplant recipients were enrolled in the study.

Results: A total of 114 renal transplant recipients with a mean age of $37.56 \pm 11.10$ years were studied. The immunosuppressive regimen consisted of combinations including tacrolimus, prednisolone, mycophenolate mofetil/ azathioprine along with supportive medications like antivirals, antibiotics and antihypertensives. Out of all those studied, 60 patients had a total of 61 cutaneous manifestations. The mean duration from date of transplantation to presentation to the transplant OPD for infectious dermatoses was 688.4 days (1.88 years) and for iatrogenic dermatoses was 67.5 days. The most common cutaneous manifestation was acne (41\%) followed by fungal infections (27.9\%) consisting of pityriasis versicolor $(n=9)$, dermatophytosis $(n=6)$ and candidiasis $(n=2)$; viral infections $(18 \%)$ consisting of verruca $(n=4)$, herpes zoster $(n=4)$ and herpes simplex $(n=3)$; bacterial infections $(4.9 \%)$ consisting of folliculitis $(n=2)$ and erythema chronicum migrans $(n=1)$. Gingival hyperplasia was observed in a single patient. Other cutaneous manifestations like seborrheic dermatitis and xerosis were also observed in 2 patients each during the study.

Conclusion: Renal transplant recipients are susceptible to acquire various cutaneous manifestations as a result of long term immunosuppression and also due to adverse effects of the drugs used. This knowledge helps the transplant physicians for regular dermatologic screening of these patients for early diagnosis and treatment of the skin lesions.
\end{abstract}

Key words: Folliculitis; Kidney Transplantation; Tacrolimus; Tinea

\section{Introduction}

W th the advent of newer drugs, therapeutic regimens and sophisticated drug-level monitoring, the average life span of the renal transplant recipients has increased. The availability

Funding: No

Conflict of Interest: No

\section{Address of Correspondence}

Dr. Anil Kumar Das

Associate Professor

Department of Dermatology and Venereology, Maharajgunj Medical Campus, Institute of Medicine, Tribhuvan University, Kathmandu, Nepal.

Ph. No.: 9851036827

E-mail: dranildas@gmail.com of potent immunosuppressants has paved the path towards decreased incidence of graft rejection and long term survival of the recipients. ${ }^{1,2}$ But, with the

Submitted: $15^{\text {th }}$ September 2020

Accepted: $30^{\text {th }}$ December 2021

Published: $20^{\text {th }}$ February 2021

How to cite this article

Das AK, Sharma R, Karn A. Cutaneous Manifestations in Renal Transplant Recipients. Nepal Journal of Dermatology, Venereology \& Leprology 2021;19(1):42-9. https://doi. org/10.3126/njdvl.v19i1.30974.

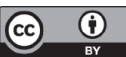

Licensed under CC BY 4.0 International License which permits use, distribution and reproduction in any medium, provided the original work is properly cited. 
increased life span of the patients and long term use of immunosuppressants, there has been an increase in various skin conditions; some benign and some lifethreatening. The common skin manifestations include various infections and malignancies. Incidence of fungal, viral, bacterial infections and non-melanoma skin cancer (Squamous cell carcinoma, Basal cell carcinoma), pre-cancerous lesions is quite high in the renal transplant recipients (RTRs) compared to the general population..$^{3-5}$

A good understanding of the possible risks associated with renal transplant and adverse effects of the drugs used and possible cutaneous manifestations post-transplant, helps us in proper counselling to the patients regarding the preventive measures, adherence to therapy and better understanding of the disease condition

Most of the cutaneous manifestations observed in RTRs are a result of immunosuppression; some, however, are drug-specific adverse effects. ${ }^{6}$

\section{Objective}

To determine the frequency and clinical pattern of cutaneous manifestations in renal transplant recipients.

\section{Materials and Methods}

This study was conducted for a period of one year from June 2013 to May 2014 in Tribhuvan University Teaching Hospital, Dermatology and Venereology Out Patient Department. The study population included renal transplant recipients attending the Transplant OPD and Dermatology OPD whose transplant was done at Tribhuvan University Teaching Hospital, Kathmandu, Nepal. One hundred and fourteen renal transplant recipients were enrolled in the study.

After taking written informed consent, patients attending the Transplant OPD or the Dermatology OPD were interviewed regarding their demographic details, indication of transplant, date of transplant, drugs they had been taking and presence of any cutaneous conditions. Details of the findings like duration of the presence of the dermatosis, its site, size and type were noted in a pre-set proforma. All diagnoses except one were made based on clinical examination only. In a single case, histopathological examination, as part of a diagnostic armamentarium, was used.

Findings were recorded, compiled and tabulated throughout the study period. SPSS 20.0 was used for statistical analysis. Descriptive statistics were compiled.

\section{Results}

A total of 114 patients were interviewed and examined in the study conducted from June 2013 to May 2014.

The mean age was $37.56 \pm 11.10$ years; minimum age being 14 years and maximum 64 years (Table 1 ).

Of the total 114 patients enrolled in the study, 97 (85\%) were male and 17 (15\%) were female (Figure 1).

Among the study population, cutaneous manifestation was observed in 60 (53\%) patients. No cutaneous manifestations were seen in 54 patients (47\%) (Figure 2).

Among the patients with cutaneous manifestations, $30(50 \%)$ had infections, 29 (48\%) had non- infectious dermatoses and $1(2 \%)$ had both infectious and noninfectious dermatoses (Figure 3).

Out of the 31 patients with infectious manifestations, $3(10 \%)$ had bacterial infection, 11 (35\%) had viral infection and 17 (55\%) had fungal infection (Figure 4).

A total of 3 patients had bacterial infection. Among them, 2 cases were of folliculitis and 1 case was erythema chronicum migrans (Figure 5).

Among 17 patients with fungal infection, 2 (12\%) had candidiasis, 9 (53\%) had pityriasis versicolor and 6 (35\%) had dermatophyte infection (Figure 6).

Out of 11 cases of viral infections, 4 (36\%) had verruca, $4(36 \%)$ had herpes zoster and $3(28 \%)$ patients had herpes simplex (Figure 7).

Among 30 patients with non-infectious dermatoses, $26(87 \%)$ had developed iatrogenic dermatoses that included drug-induced acne and gingival hyperplasia. Miscellaneous skin manifestations including seborrheic dermatitis and xerosis was observed in 4 (13\%) of patients. Cutaneous malignancies, however, was not observed in any renal transplant recipient.

\section{Duration from date of transplantation to presentation}

\section{Infectious dermatoses}

The mean duration from date of transplantation to presentation to the transplant OPD for infectious dermatoses was 688.4 days ( 1.88 years) with a range 
of a minimum of 21 days to maximum of 1906 days (5.22 years).

\section{latrogenic dermatoses}

The mean duration from date of transplantation to presentation to the transplant OPD for iatrogenic dermatoses was 67.5 days with a range of a minimum of 5 days to maximum of 1113 days. Leaving aside the case of gingival hyperplasia, the mean duration of appearance of acne was 31.9 days.

\section{Miscellaneous dermatoses}

Two patients with seborrheic dermatitis presented at day 86 and day 175 of transplant.

Two patients with xerosis presented at day11 and day170 of transplant.

Table 1: Age distribution of renal transplant recipients

\begin{tabular}{|c|c|c|}
\hline $\begin{array}{c}\text { Age } \\
\text { Distribution (years) }\end{array}$ & Number & Percent \\
\hline$<20$ & 6 & 5.3 \\
\hline $20-29$ & 26 & 22.8 \\
\hline $30-39$ & 42 & 36.8 \\
\hline $40-49$ & 24 & 21.1 \\
\hline $50-59$ & 13 & 11.4 \\
\hline$\geq 60$ & 3 & 2.6 \\
\hline Total & 114 & 100.0 \\
\hline
\end{tabular}

Table 2: Distribution of patients with cutaneous manifestation according to their duration of presentation from date of transplant.

\begin{tabular}{|l|c|c|}
\hline $\begin{array}{l}\text { Duration from transplant } \\
\text { to presentation }\end{array}$ & $\begin{array}{c}\text { Number of } \\
\text { patients }\end{array}$ & Percent \\
\hline$<7$ days & 6 & 10.0 \\
\hline 7days-1 month & 16 & 26.7 \\
\hline 1-3 months & 9 & 15.0 \\
\hline 3 months - 1 year & 8 & 13.3 \\
\hline$>1$ year & 21 & 35.0 \\
\hline Total & $\mathbf{6 0}$ & $\mathbf{1 0 0 . 0}$ \\
\hline
\end{tabular}

Table 3: Summary of the cutaneous manifestations in renal transplant recipients

\begin{tabular}{|l|c|c|}
\hline $\begin{array}{l}\text { Cutaneous } \\
\text { manifestations }\end{array}$ & $\begin{array}{c}\text { Number of } \\
\text { cases }\end{array}$ & Percentage \\
\hline Bacterial infection & 3 & 4.9 \\
\hline Folliculitis & 2 & 3.3 \\
\hline $\begin{array}{l}\text { Erythema Chronicum } \\
\text { Migrans }\end{array}$ & 1 & 1.6 \\
\hline Fungal infection & 17 & 27.9 \\
\hline Pityriasis versicolor & 9 & 14.8 \\
\hline
\end{tabular}

\begin{tabular}{|l|c|c|}
\hline Dermatophyte infections & 6 & 9.8 \\
\hline Candidiasis & 2 & 3.3 \\
\hline Viral infection & 11 & 18.0 \\
\hline Herpes Zoster & 4 & 6.6 \\
\hline Herpes Simplex & 3 & 4.9 \\
\hline Verruca & 4 & 6.6 \\
\hline latrogenic dermatoses & 26 & 42.6 \\
\hline Acne & 25 & 41.0 \\
\hline Gingival Hyperplasia & 1 & 1.6 \\
\hline $\begin{array}{l}\text { Miscellaneous } \\
\text { dermatoses }\end{array}$ & 4 & 6.6 \\
\hline Seborrheic dermatitis & 2 & 3.3 \\
\hline Xerosis & 2 & 3.3 \\
\hline Total & 61 & \\
\hline
\end{tabular}

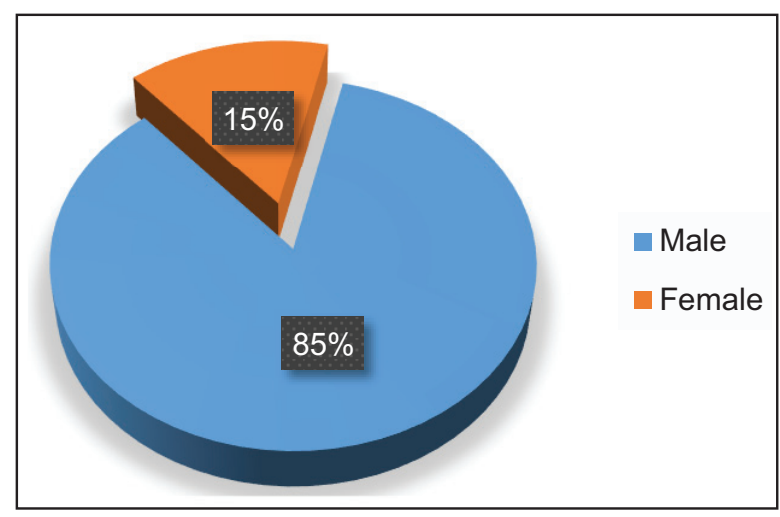

Figure 1: Gender wise distribution of renal transplant recipients in the study

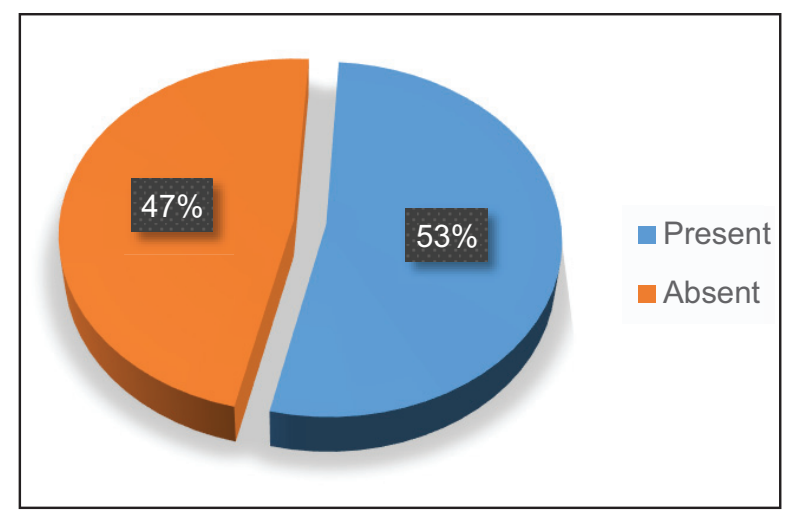

Figure 2: Presence of cutaneous manifestations 


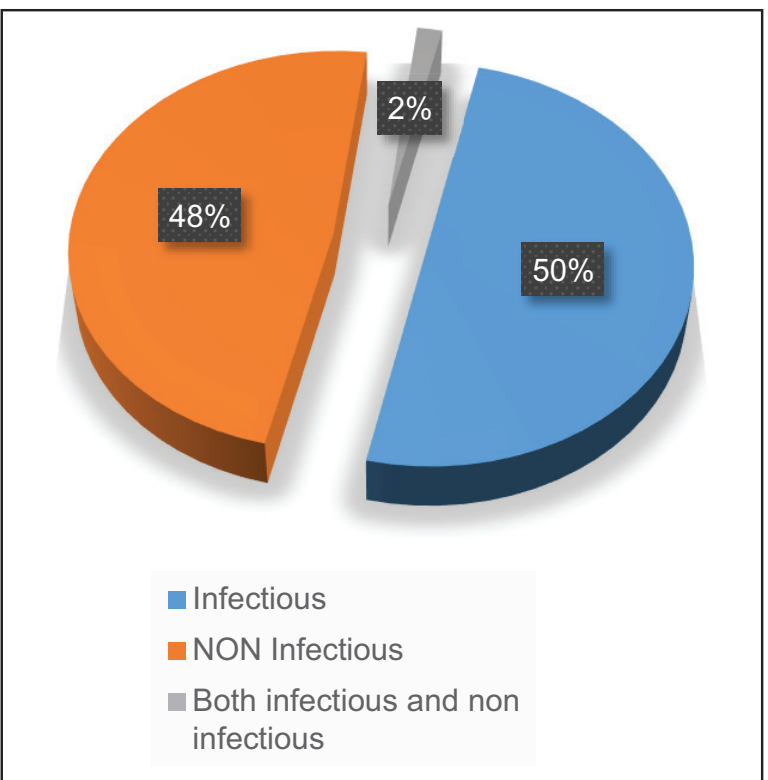

Figure 3: Types of cutaneous manifestations.

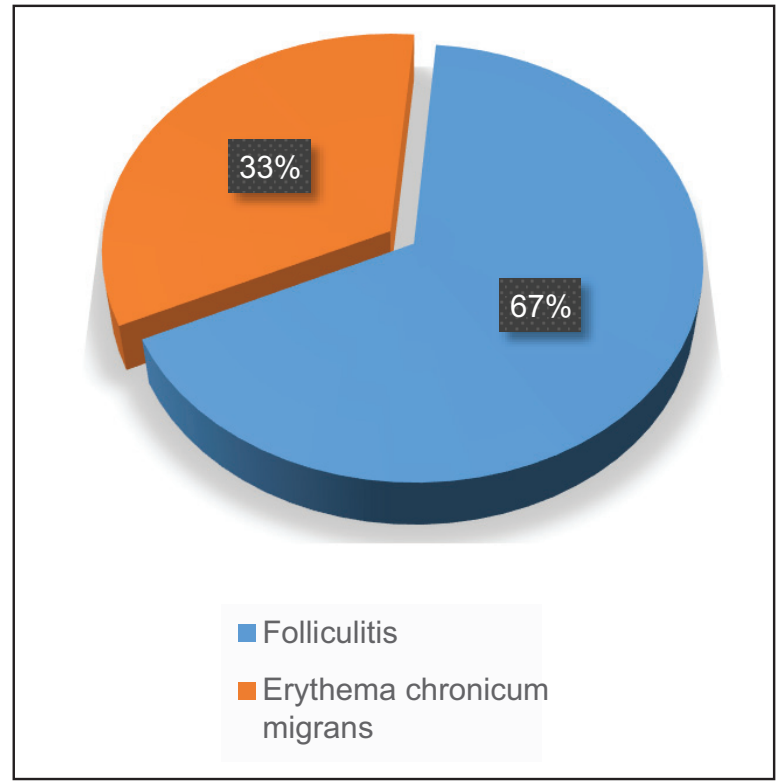

Figure 5: Types of bacterial infections

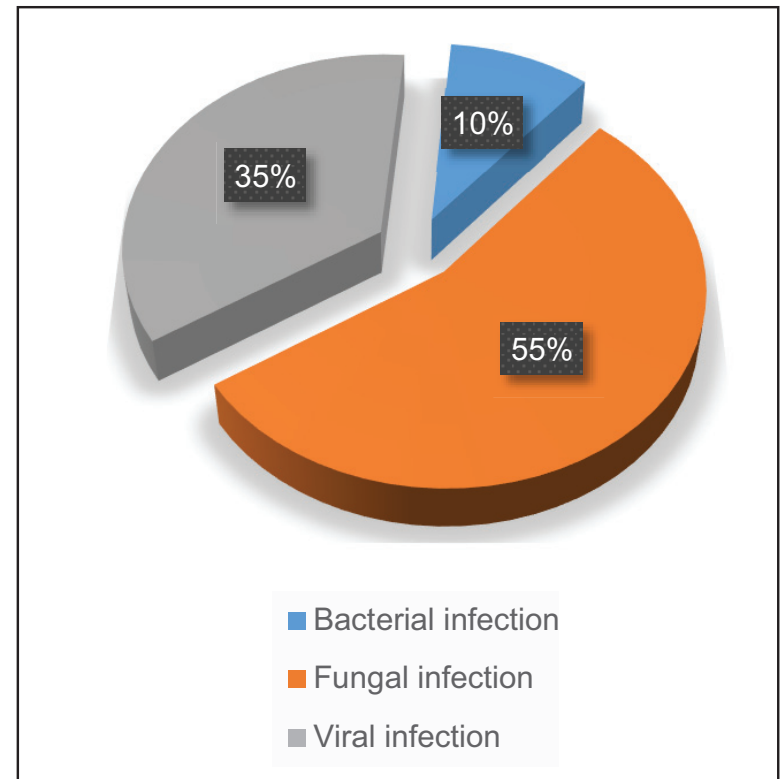

Figure 4: Types of infectious cutaneous manifestations.

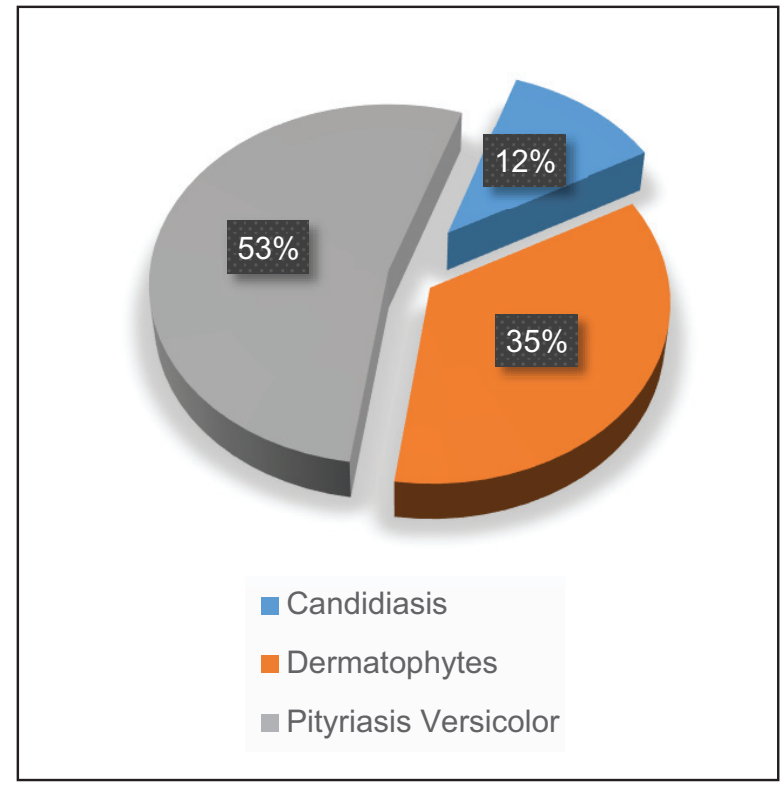

Figure 6: Types of fungal infections

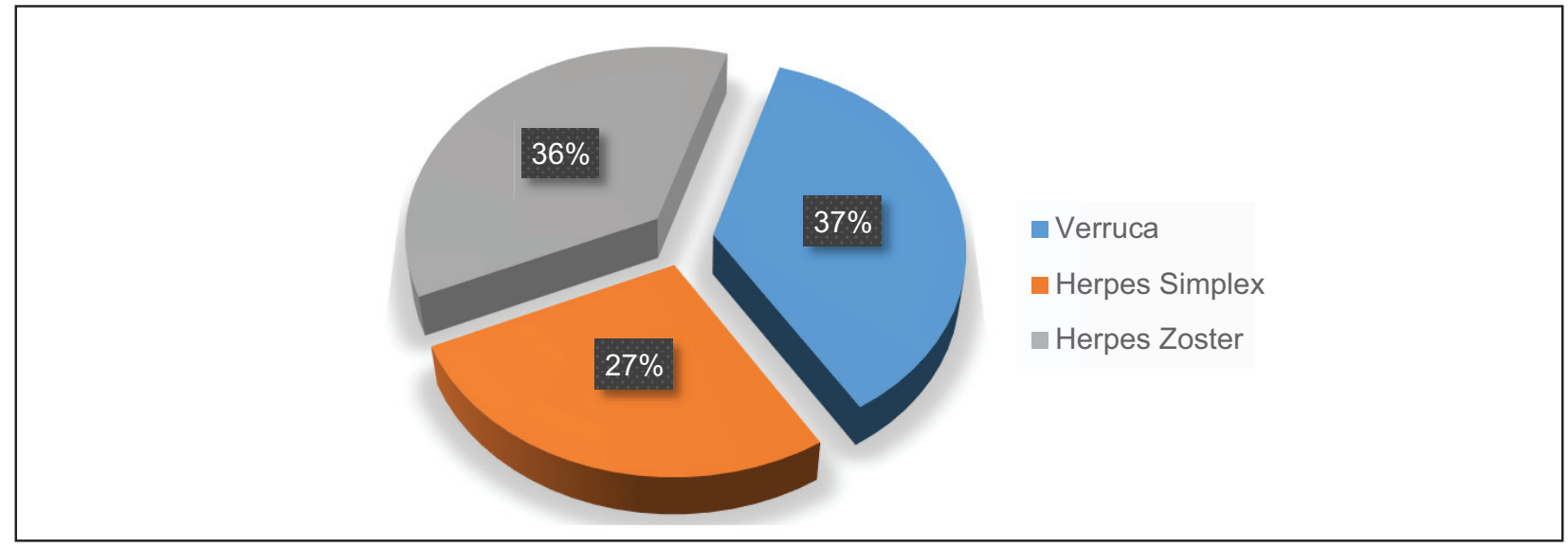

Figure 7: Types of viral infections 


\section{Discussion}

This study evaluated the cutaneous manifestations among renal transplant recipients in the transplant OPD, Tribhuvan University Teaching Hospital. The most common indication for renal transplant in these patients was found out to be hypertensive nephropathy.

Cutaneous manifestation was observed in about 53\% of the renal transplant recipients studied and no skin findings were seen in the rest $47 \%$ of them. A total of 61 skin lesions were observed in 60 patients. Infectious skin lesions (50.8\%) were more common than non-infectious (49.2\%). Ninety-one cutaneous manifestations were identified in 60 of 109 (55.0\%) kidney transplant patients over a 4-year period in a study done in Italy by Formicone et $a l^{6}$. In a study done in Uruguay by Dufrechou et $a^{9}{ }^{9}$ in renal and renopancreatic transplant recipients, infectious lesions comprised of $27.9 \%$ of the total.

Bacterial infection comprised of total of 3 cases (4.9\%); 2 cases of folliculitis (3.3\%) and a single case of erythema chronicum migrans (1.6\%). Bacterial folliculitis is a common manifestation in transplant recipients as observed in other studies. In a study of 178 renal transplant recipients in Iran by Khosravi et al,

${ }^{10}$ two cases of folliculitis were found. A higher number of bacterial infection were seen in a study done in India by Prakash et al. ${ }^{8}$

Erythema chronicum migrans, in the United States is caused by the tick-transmitted spirochete Borrelia burgdorferi. ${ }^{11}$ This infection is the most common vectorborne disease in the United States (US). ${ }^{12}$ Since the patient who was diagnosed with Erythema chronicum migrans in this study used to visit United States frequently, she could have acquired the condition back in the US, and this could be just an incidental finding. Erythema chronicum migrans is not a common finding in general population in our part of the world. This case of Erythema chronicum migrans was diagnosed on the basis of histopathological examination.

A total of 17 cases (27.9\%) of fungal infection were recorded in this study which consisted of 2 cases (3.3\%) of Candidiasis, 9 cases (14.8\%) of pityriasis versicolor and 6 cases ( $9.8 \%$ ) of dermatophyte infections. In a casecontrol study done in 102 renal transplant recipients by Gulec et al, ${ }^{65}$ pityriasis versicolor and cutaneous candidiasis were found to be significantly common in transplant recipients compared to the general population; $36.3 \%$ patients had pityriasis versicolor,
$25.5 \%$ had candidiasis, $12.7 \%$ had onycomycosis and $11.8 \%$ had toe web infection. Similarly, 19 (20.8\%) superficial fungal infections among 13 of 109 (11.9\%) kidney transplants was observed in a study done by Formicone et $a l .{ }^{6}$ In the same study, dermatophytosis and onycomycosis were most commonly observed fungal infections followed by pityriasis versicolor and mucocutaenous candidiasis. ${ }^{6}$ Oncycomycosis was the commonest infection as a whole comprising of $58 \%$ of total infections. Dermatophytosis (10\%) and pityriasis versicolor (6\%) followed, in a study done by Sandoval et $\mathrm{al}^{100}$ in Chile. In the study done in India by Prakash et $a l,{ }^{8}$ they noted pityriasis versicolor, tinea ungium and mucocutaneous candidiasis in $20.3 \%, 7.4 \%$, and $5.5 \%$ of cases, respectively which is similar to the results in our study. These two countries falling into the same geographical region with similar prevalence among the general population also explains the similar findings in terms of infectious lesions. ${ }^{8}$

A total of 11 cases (18\%) of viral infection were found in our study which included $4(6.6 \%)$ herpes zoster, $4(6.6 \%)$ verruca and $3(4.9 \%)$ herpes simplex. Two of the patients of herpes zoster, though young, had extensive, multi dermatomal involvement which could be due to the fact that they were under high degree of immunosuppression because of the drugs they were taking after the transplant. Twenty seven cases of verruca, 3 cases each of herpes zoster and herpes simplex and 1 case of molluscum contagiosum were present in a study of 178 cases of renal transplant by Khosravi et al ${ }^{10}$ which is a similar finding as in our study. Sixteen (17.5\%) cutaneous viral infections were identified in 11 of 109 patients (10.0\%) in a study conducted by Formicone et al. ${ }^{1}$ Verruca vulgaris, observed in nine of those patients, was the most common viral infection, followed by herpes zoster in 5 and herpes simplex in 2 patients. One of the patients with herpes zoster had disseminated lesions, one had multidermatomal involvement and the remaining three patients had lesions confined to a single dermatome. Prakash et $a l^{4}$ reported $3.7 \%$ of herpes simplex infections and $9.2 \%$ of herpes zoster cases in their study, a finding similar to our study

A total of 30 non-infectious dermatoses were noted in our study which included 26 dermatoses known to be directly associated with the drugs used in the transplant and 4 lesions classified as miscellaneous that included seborrheic dermatitis and xerosis. Acne consisted the majority of these lesions (41\% of the total cutaneous manifestations). One case of gingival hyperplasia was also noted. Cutaneous side effects of immunosuppressive drugs were observed 
in $58 \%$ of patients in a study done by $\mathrm{M}$. Sandoval et $a l^{13}$. On contrary to what is seen in our study, this study presents more number of adverse effects besides acne. However, all of those adverse effects can be explained by the use of prednisolone which is a common drug in most of the regimens used in organ transplants throughout the world, though the transplant regimen has not been clearly mentioned in the study. In another study conducted by Khosravi et $a l,{ }^{10}$ gingival hyperplasia was the most common lesion (48\%) among the iatrogenic lesions. Cyclosporine was a major component of the drug regimen resulting in immunosuppression, in this study, and it has been clearly linked to gingival hyperplasia by many studies. On head to head comparison, incidence of gingival hyperplasia has been shown to be minimal to none in transplant recipients receiving tacrolimus in place of cyclosporine. ${ }^{14}$ In our center, tacrolimus is used instead of cyclosporine in renal transplantation and this explains the single case of gingival hyperplasia. However, calcium channel blockers like Nifedipine and Diltiazem can also independently cause gingival hyperplasia. ${ }^{15}$ Diltiazem was a part of the drug regimen in our patient who developed gingival hyperplasia and this could explain the presence of this condition in our patient in absence of cyclosporine.

Twenty-six of 109 (23.8\%) patients developed 32 drug related cutaneous manifestations: acneiform eruptions were observed in 14 patients, gingival hypertrophy in six, hypertrichosis in 6 , ecchymosis in 3 and plantar hyperkeratosis in 3 , in a study done by Formicone et al. ${ }^{6}$ In another study by Prakash et al, ${ }^{4} 7$ cases of gum hypertrophy, 7 cases of hypertrichosis, 7 cases of cushingoid features and 3 cases of acne were noticed. Most of the adverse effects known to be associated with the drugs used have not been observed in our study; however, acne consists of majority of the cutaneous manifestations (41\%). Most cases of acne were seen in the initial few days to weeks of follow up when the dose of prednisolone was relatively higher. With gradual tapering of the dose of prednisolone, the drug-induced acne resolved spontaneously. Most of the patients who were enrolled in the study gave a history of developing acne at some point of time immediately after transplant though not all of them had those lesions at the time of examination since this was a cross-sectional study.

Though multiple cutaneous adverse reactions ranging from mild to severe, with the use of diltiazem have been identified in the literature, ${ }^{16}$ none of these were observed during our study period.
Premalignant conditions of the skin and cutaneous malignancies are and important adverse outcome of organ transplant which occur as a result of long term immunosuppression in the transplant recipients. There is a striking difference in both incidence and prevalence of cutaneous malignancies between the Caucasians and the Asian population. The incidence and prevalence is even less in population with Fitzpatrick skin type IV and V like that of the Indian subcontinent.

Not a single case of a premalignant skin lesion or any cutaneous malignancy was noted in our study which is consistent with other studies done in the tropical countries of Asia in which population also the incidence and prevalence of these conditions is rare. Prakash et $a l$, in his study in India, reported no cases of cutaneous malignancies. However, abundance of literature regarding skin malignancies in transplant recipients in the western population highlights the importance of recognition of the threat posed by these conditions.

Skin cancers are the most common malignant conditions in organ transplant recipients: squamous cell carcinoma and basal cell carcinoma account for more than $90 \%$ of all skin cancers. The incidence of non-melanoma skin cancers increases with the level of immunosuppression, occurring in $10 \%$ to $43 \%$ of the patients within 10 years after transplantation and in $40 \%$ to $80 \%$ after 20 years. SCC is 65 to 250 times more frequent among transplant recipients than in the general population, while BCC is 10 times more common. ${ }^{17}$

Fifteen actinic keratosis, 1 Bowen's disease and 1 squamous cell carcinoma was noted in a study done by Sandoval et al. ${ }^{13}$ Relevant to our context is a retrospective study done in Korea which revealed that the 15-year cumulative incidence of cutaneous malignancies in Korean population is $2.3 \%$ (95\% confidence interval, $1.2 \%-3.4 \%$ ), but the risk after the fifth post-transplantation year is 30.9 -fold (95\% confidence interval, 12.4-63.6) higher compared with the Korean general population. This large increase in the risk alerts us to the possibility of skin cancers in Korean organ transplant recipient. ${ }^{8}$ Though no cases were seen in our study, with increasing duration of immunosuppression, patients might go on to develop cutaneous malignancies and transplant physicians as well as dermatologists should be well aware of this fact. It has been just over 6 years since renal transplant began at our institute so it might be too early to rule out the increased risk of cutaneous malignancies 
in transplant recipients compared to the general population.

There were 4 cases (6.6\%) classified as miscellaneous cutaneous manifestations which include 2 cases of seborrheic dermatitis and 2 cases of xerosis, in this study. These were classified as miscellaneous since they could not be correlated directly to immunosuppression or to any adverse effects to specific drugs. Dufrechou et $a l,{ }^{9}$ in their study, recorded a total of 23 cases (22.1\%) of miscellaneous skin conditions in renal transplant recipients. Similarly, 5 cases of psoriasis and 3 cases of seborrheic dermatitis was observed in a study by Formicone et al. ${ }^{6}$

The mean duration from date of transplantation to presentation to the transplant OPD for infectious lesions was calculated to be 688.4 days ( 1.88 years) which is consistent with the finding that most cases of opportunistic infection occur in the time frame of beyond 6 months of transplantation. ${ }^{72}$ That included all the cases of herpes simplex, herpes zoster and verruca and most of the cases of fungal and bacterial infections. Only 2 cases of dermatophyte infections, 3 cases of candidiasis and 1 case of pityriasis versicolor appeared in the time frame of one through six months.

The mean duration from date of transplantation to presentation to the transplant OPD for iatrogenic lesions was 67.5 days. One of the cases was gingival hyperplasia and all the other were drug-induced acne. Leaving aside the case of gingival hyperplasia, the mean duration of appearance of acne was 31.9 days, which might be correlated with relatively higher dose of prednisolone in the first few days of transplant and pulse methylprednisolone on the first day of transplant.

\section{Conclusion}

This study shows that there are a myriad of cutaneous manifestations in renal transplant recipients. They are susceptible to infectious pathologies and at the same time, might fall victim to adverse effects of plenty of drugs used for immunosuppression after the transplant. With increased duration of transplant i.e. longer duration of immunosuppression, there is an increased risk of developing infectious skin lesions. With this knowledge about the cutaneous manifestations in the transplant recipients, the physicians need to be aware regarding proper dermatologic screening, prompt diagnosis and proper treatment of these conditions.

\section{Limitations of the study}

- The cross-sectional descriptive design of the study is its main limitation. It would have been better if all the patients were studied at every visit since the first follow up.

- The duration of the study: with increasing duration of immunosuppression, renal transplant recipients are prone to develop cutaneous manifestations. So, a larger population could have been observed with much varied cutaneous manifestations had the duration of study had been many years.

\section{References}

1. Geissler EK. Can immunosuppressive strategies be used to reduce cancer risk in renal transplant patients? Transplantation proceedings. 2010;42(9 Suppl):S32-5. https://doi.org/10.1016/j. transproceed.2010.07.004

2. Mycophenolate mofetil in renal transplantation: 3-year results from the placebo-controlled trial. European Mycophenolate Mofetil Cooperative Study Group. Transplantation. 1999;68(3):391-6. https://doi.org/10.1097/00007890-19990815000011

3. Barba A, Tessari G, Boschiero L, Chieregato GC. Renal transplantation and skin diseases: review of the literature and results of a 5-year follow-up of 285 patients. Nephron. 1996;73(2):131-6. https:// doi.org/10.1159/000189029

4. Bouwes Bavinck JN, Hardie DR, Green A, Cutmore S, MacNaught A, O'Sullivan B, et al. The risk of skin cancer in renal transplant recipients in Queensland, Australia. A follow-up study. Transplantation. 1996;61(5):715-21. https://doi. org/10.1097/00007890-199603150-00008

5. London NJ, Farmery SM, Will EJ, Davison AM, Lodge JP. Risk of neoplasia in renal transplant patients. Lancet. 1995;346(8972):403-6. https:// doi.org/10.1016/S0140-6736(95)92780-8

6. Formicone F, Fargnoli MC, Pisani F, Rascente $M$, Famulari A, Peris K. Cutaneous manifestations in Italiankidneytransplantrecipients. Transplantation proceedings. 2005;37(6):2527-8. https://doi. org/10.1016/j.transproceed.2005.06.067

7. Prakash J, Singh S, Prashant GK, Kar B, Tripathi K, Singh PB. Mucocutaneous lesions in transplant 
recipient in a tropical country. Transplantation proceedings. 2004;36(7):2162-4. https://doi. org/10.1016/j.transproceed.2004.08.011

8. Park $\mathrm{GH}$, Chang $\mathrm{SE}$, Won $\mathrm{CH}$, Lee $\mathrm{MW}$, Choi $\mathrm{JH}$, Moon KC, et al. Incidence of primary skin cancer after organ transplantation: An 18year single-center experience in Korea. Journal of the American Academy of Dermatology. 2014;70(3):465-72. https://doi.org/10.1016/j. jaad.2013.10.024

9. Dufrechou L, Larre Borges A, Nin M, Curi L, Gonzalez F, Martinez $M$, et al. Cutaneous manifestations in 100 renal and reno-pancreatic recipients of Uruguay. Transplantation proceedings. 2011;43(9):3377-9. https://doi. org/10.1016/j.transproceed.2011.09.088

10. Khosravi M, Golchai J, Mokhtari G. Mucocutaneous manifestations in 178 renal transplant recipients. Clinical transplantation. 2011;25(3):395-400. https://doi.org/10.1111/ j.1399-0012.2010.01284.x

11. Steere AC. Lyme disease. The New England journal of medicine. 2001;345(2):115-25. https:// doi.org/10.1056/NEJM200107123450207

12. Orloski KA, Hayes EB, Campbell GL, Dennis DT. Surveillance for Lyme disease--United States, 1992-1998. MMWR CDC surveillance summaries
: Morbidity and mortality weekly report CDC surveillance summaries / Centers for Disease Control. 2000;49(3):1-11.

13. Sandoval M, Ortiz M, Diaz C, Majerson D, Molgo $M$. Cutaneous manifestations in renal transplant recipients of Santiago, Chile. Transplantation proceedings. 2009;41(9):3752-4. https://doi. org/10.1016/j.transproceed.2009.05.041

14. Tanabe K. Calcineurin inhibitors in renal transplantation: what is the best option? Drugs. 2003;63(15):1535-48. https://doi. org/10.2165/00003495-200363150-00002

15. Giustiniani S, Robustelli della Cuna F, Marieni M. Hyperplastic gingivitis during diltiazem therapy. International journal of cardiology. 1987;15(2):247-9. https://doi.org/10.1016/01675273(87)90322-6

16. Knowles S, Gupta AK, Shear NH. The spectrum of cutaneous reactions associated with diltiazem: three cases and a review of the literature. Journal of the American Academy of Dermatology. 1998;38(2 Pt 1):201-6. https://doi.org/10.1016/ S0190-9622(98)70241-5

17. Euvrard S, Kanitakis J, Claudy A. Skin cancers after organ transplantation. The New England journal of medicine. 2003;348(17):1681-91 https://doi. org/10.1056/NEJMra022137. 